Article

\title{
Stress Relaxation Related to Spontaneous Thin Film Buckling: Correlation between Finite Element Calculations and Micro Diffraction Analysis
}

\author{
Haikun Jia ${ }^{1}$, Shi Bin Wang ${ }^{2}$, Nobumichi Tamura ${ }^{3}{ }^{3}$ and Philippe Goudeau ${ }^{4, *}$ \\ 1 China Electric Power Research Institute, Nº15, Xiaoying Rd(E), Qinghe, Beijing 100192, China; \\ jiahaikun@epri.sgcc.com.cn \\ 2 Department of Mechanics, Tianjin University, Tianjin 300072, China; shbwang@tju.edu.cn \\ 3 Advanced Light Source-Lawrence Berkeley National Laboratory (ALS-LBNL), 1 Cyclotron Road, MS 2-400, \\ Berkeley, CA 94720, USA; ntamura@lbl.gov \\ 4 Institut Pprime, UPR 3346 CNRS-Université de Poitiers - ENSMA, BP 30179, 86962 Futuroscope, France \\ * Correspondence: philippe.goudeau@cnrs.pprime.fr; Tel.: +33-549-496-726
}

Received: 1 November 2018; Accepted: 18 December 2018; Published: 20 December 2018

\begin{abstract}
Compressive residual stresses generated during thin film deposition may lead to undesirable film damage, such as delamination, buckling, and flaking, ultimately leading to the failure of the device employing the film. Understanding the residual stress generation and role in these damage mechanisms is necessary to preserve thin film integrity and optimize its functional properties. Thin shell theory has been used for decades to predict buckling but the results have not yet been correlated with experimental data since the techniques used to measure stress in metallic films were not able to do so at the required micron scale until recently. Micro scanning X-ray diffraction now enables the direct mapping of the local stress of metallic films. In this paper, finite element method based on thin shell theory and synchrotron X-ray micro diffraction have been used to determine stress maps of thin film buckling patterns. Calculations of the stress distribution in the metallic films have been performed taking into account the buckling geometry determined from optical measurements. Stress distributions over gold blisters and tungsten wrinkles obtained with the two techniques are in fair agreement and allow for the accurate determination of the stress relaxation profile from the bottom to the top of the buckling, validating the thin shell theory model.
\end{abstract}

Keywords: metallic thin films; residual stresses; delamination; synchrotron X-ray diffraction; finite element method (FEM); strain/stress measurements

\section{Introduction}

The phenomenon of stress buildup during film deposition on substrates has been known for many years. In particular, the role of these residual stresses in applications using film/substrate systems such as microelectronic devices and manufacturing cutting tools may be dramatic, leading to device failure or protective properties' modifications. Thin films are often under compressive stresses [1], especially when sputtering deposition techniques are applied.

Increasing the thickness of the compressed thin film leads to an increase in the total elastic energy stored in the film, which is often locally relaxed through the appearance of damage, such as wrinkles or blisters, and subsequent fractures or spalling for brittle materials when stresses reach high values. Indeed, it is well known that buckling of thin film is linked to elastic instability that releases stresses in the film. Wrinkles generated in thin films have been studied by several authors [2-7]. Theoretical and numerical calculations based on Föpple-Von Karman equations have been performed for several typical modes (straight-sided wrinkle, telephone cord wrinkle, circular blister) [6,8-10]. However, these equations 
cannot be used in more complex topologies where several buckles exist in one macroscopic region of the thin film. Furthermore, correlative studies of the veracity and trend of the distribution of experimental stresses, with theoretical or numerical analysis of buckling patterns after the delamination of thin films, are less common. This means that numerical stress prediction or experimental stress measurements of complex buckling patterns at the micron scale are still open questions [11,12]. It is therefore important to determine the effective stress field associated with local damages. However, determination of residual stresses in thin films is often performed experimentally over the global film surface, mapping of the local stress distribution being rarely performed for metallic films [13].

At the macroscopic scale, the residual stresses obtained by X-ray diffraction were compared to the simulation results from finite elements method (FEM) for the case of small deformations [14]. However, the microscopic sizes of the buckles have so far prevented direct measurement of strain and stress distributions over the buckling region to support these theoretical and numerical results. Wafer curvature measurement techniques based on Stoney's equation are used to measure the overall average stress in these films, but do not have the spatial resolution needed to map in-plane strain/stress of a single buckling [15]. Thus, the film stresses are usually considered as uniform in the film plane.

Cross-sectional nanodiffraction has been developed at synchrotron facilities to characterize the nanoscale depth variation of residual stresses and microstructure in thin films and coatings [16]. More recently, focused ion beam (FIB)-based techniques have been used to understand how residual stress is distributed across the scales analyzing relaxation phenomena $[17,18]$. Note that all these above-mentioned techniques are invasive. Some experimental tests have been recently performed using micro-scanning X-ray diffraction ( $\mu \mathrm{SXRD}$ ) and Raman spectroscopy to map in-plane stress in different types of thin films $[11,13,19]$. The micro-Raman technique may be applied for stress mapping at a micron scale and recent works have illustrated its potential for thin film wrinkles $[11,20]$. However, this technique may only be considered for specific materials, such as ceramics, oxides and semiconductors with well-defined microstructure, and thus does not work for metals [20]. X-ray microbeams available at third-generation synchrotron radiation sources are now widely used in material science and for biological applications. Recent studies in cell biology, environmental science and microbiology using hard X-ray microprobes have yielded promising results [21]. In the case of single crystals or when the X-ray beam is smaller than the crystallite size, Laue $\mathrm{X}$-ray diffraction using a polychromatic X-ray beam allows for microstructure and strain/stress mapping measurements with submicrometre spatial resolution in three dimensions [22,23]. In the cases of nanocrystalline thin films (i.e., with nanometric grain size), this technique cannot be applied because nanometric $X$-ray spot sizes are not yet available.

In this work, stress mapping of buckling patterns of thin film deposited on silicon substrates is investigated by micro-scanning monochromatic $\mathrm{X}$-ray diffraction and finite element analysis. Use of $\mu S X R D$ to measure the distribution of stresses is now classical and was performed for the first time in gold and tungsten films using the $\sin ^{2} \Psi$ method [13]. This characterization technique is very useful to study systems developing mechanical instability such as film/substrate systems $[4,10]$, especially when buckling occurs. Consequently, investigations of individual buckling patterns have been performed. Firstly, we will present buckling effects due to residual stresses and associated topological aspects thanks to optical measurements. Then, we will discuss the $\mathrm{X}$-ray diffraction technique for stress measurements over buckling patterns. As a consequence of residual stresses relaxation in the buckling region, buckling topologies and associated stress maps are calculated using FEM. Spontaneous buckling phenomenon occurs often after film deposition (i.e., when taking the sample out of the deposition chamber), and is known to release the residual stresses in the film $[6,9,21]$. However, in the bonded region of the thin films, the residual stresses are considered as equi-biaxial. Modeling of stress distribution is possible but quite difficult and depends strongly on buckling geometry [24]. Moreover, in order to investigate the mechanical stability of thin films and the service life of film/substrate systems, it is necessary to measure the stress in the debonded region. We have considered only the instability question of the buckling in the finite element modeling, the adhesion at 
the interface being ignored (buckling propagation is not our purpose). Finally, comparison between $\mu \mathrm{SXRD}$ and modeling results is discussed.

\section{Sample Preparation}

Polycrystalline thin films of 630-nm-thick gold $(\mathrm{Au})$ and 300-nm-thick tungsten $(\mathrm{W})$ were deposited at room temperature by ion beam sputtering on a 650- $\mu \mathrm{m}$-thick (100) Si wafer covered with native oxide. The measurements of the global stress values of the adherent parts of Au and W films were performed by the substrate curvature method using Stoney's equation and a 200- $\mu \mathrm{m}$-thick (100) Si wafer and thinner deposited films to avoid buckling. The global stress values were about $-400 \pm 40 \mathrm{MPa}$ for the gold films and between $-4.0 \pm 0.4$ and $-6.0 \pm 0.6 \mathrm{GPa}$ for the $\mathrm{W}$ films. The elastic moduli $E=80 / 410 \mathrm{GPa}$ and Poisson ratios $v=0.42 / 0.28$ were used for the Au and W films, respectively. Previous studies based on diffraction peak profile analysis and cross-section transmission electron microscopy have shown that typical grain size is smaller than $10 \mathrm{~nm}$ and $100 \mathrm{~nm}$ for $\mathrm{W}$ and $\mathrm{Au}$ films, respectively [25,26].

After the deposition of the thin films, biaxial compressive residual stresses in the thin film plane were observed in our samples. The residual stresses were far beyond the critical stresses, under which the films will be debonded and buckled away from the substrates. Thus, buckling patterns such as circular blisters in the Au film (see Figure 1a), a series of telephone-cord wrinkles in a macroscopic region in the W film (see Figure 1b) and a single (isolated) telephone-cord wrinkle in the W film (see Figure 1c) have been considered in this study. Morphological information of the buckling regions was subsequently obtained by optical microscopy. The stress distribution of circular blister I (diameter $=54 \mu \mathrm{m}$ ) in Figure $1 \mathrm{a}$ and the buckling region III in Figure $1 \mathrm{~b}$ were the first damages investigated using $\mu S X R D$ in a preliminary work [13]. In our current work, additional blisters and buckling have been investigated: blister II in Figure 1a, and buckling region IV in Figure 1c. All these X-ray stress maps on buckling regions I-IV in Figure 1 are compared with a stress field given by FEM simulations.

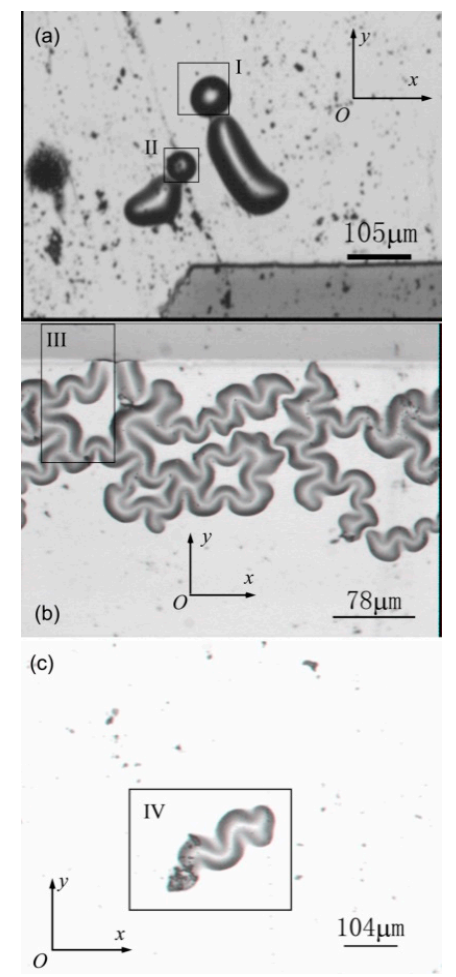

Figure 1. Morphological aspect determined by optical microscopy of (a) circular blisters in Au film, (b) a series of telephone-cord wrinkles in W film, and (c) a single and isolated telephone-cord wrinkle in W film. 


\section{Micro Scanning X-Ray Stress Measurements}

Micro scanning X-ray diffraction experiments have been performed at the Advanced Light Source (ALS) [27]. Monochromatic X-ray beam with a photon energy of $6 \mathrm{keV}(\lambda=0.2066 \mathrm{~nm})$ and a typical beam size of $3 \times 3 \mu \mathrm{m}^{2}$ has been chosen for investigating Au and $W$ thin film samples while polychromatic X-ray beam has been used for experimental geometry calibration (sample to detector distance and charge coupled device - CCD detector tilt angles). Back reflection mode is considered for the diffraction measurements and fluorescence scans are used for localizing markers on the sample surface in order to calibrate the $x$-y sample stage. The sample-to-detector distance is generally rather small (about $35 \mathrm{~mm}$ ) which allows a wide diffraction data integration range in the $45^{\circ} / 90^{\circ}$ configuration for the incident $\mathrm{X}$-ray beam angle and the angular detector position, respectively. The exposure time for each point of a scan was about $300 \mathrm{~s}$ which is time consuming for an entire mapping of 100 points (about $9 \mathrm{~h}$ ) or 1000 points (about three-and-a-half days). The diffraction patterns are analyzed using an in-house continuously evolving dedicated XMAS (X-ray microdiffraction analysis software) mainly developed for Laue pattern (white beam) [28].

A typical CCD diffraction pattern is displayed in Figure 2a. Residual stresses within a sample can be determined by measuring the induced change in lattice constant with X-rays. The analysis of the diffraction patterns consists in applying the " $d$ vs. $\sin ^{2} \Psi$ " technique $[29,30]$ to the rings, where $\Psi$ is the angle between the normal to the surface and the normal to the diffracting planes. Each point on a given ring corresponds to a different $\Psi$ value. The CCD diffraction pattern is converted into a $2 \Theta-\Psi$ frame using the precisely determined calibration geometry. Note that XRD measurements are done in one direction $\left(\mathrm{phi}=0^{\circ}\right)$. A complete description of the in-plane stresses needs additional measurements for $\mathrm{phi}=90^{\circ}$ which have not been done here; only the $\sigma_{\mathrm{xx}}$ is measured.

Figure 2 describes the $\sin ^{2} \Psi$ technique applied to the (311) ring of a diffraction pattern corresponding to $\mathrm{Au}$ film. The stress measurement is more sensitive at high diffracting angles. The presence of (111) fiber texture induces a non-homogenous distribution of diffracted intensities along the diffraction ring; a maximum is observed in the pole direction. The $\sin ^{2} \Psi$ range is thus limited to $[0.16 ; 0.32]$. The CCD frame (Figure $2 \mathrm{a})$ is divided into $N(N=1,2,3, \ldots, I)\left[\psi^{\mathrm{i}}\right]=\left[\psi_{\min }^{\mathrm{i}} \psi_{\max }^{\mathrm{i}}\right]$ intervals over which the intensity is integrated over a fixed $\left[2 \theta_{\min }, 2 \theta_{\max }\right]$ range. For each of these $\left[\Psi^{\mathrm{i}}\right]$ intervals, the intensity profile in function of $2 \Theta$ is plotted (Figure $2 \mathrm{~b}$ ) and fitted to a Lorentzian function allowing the determination of the central value $2 \theta_{c}{ }^{i}$. Each interval is assigned an $\Psi$ value $\psi^{\mathrm{i}}=\left(\psi_{\min }^{\mathrm{i}}+\psi_{\max }^{\mathrm{i}}\right) / 2$ and the corresponding d-spacing is calculated as $d_{\mathrm{i}}=1 / 2 \sin \left(\theta_{\mathrm{c}}{ }^{\mathrm{i}}\right)$. With the assumption that the average stress under the area illuminated by the $\mathrm{X}$-ray beam is biaxial with no $\sigma_{\mathrm{xy}}$ shear component, we have the classical " $d$ vs. $\sin ^{2} \Psi$ " relation:

$$
\frac{d-d_{0}}{d_{0}}=\frac{1+v_{\mathrm{f}}}{E_{\mathrm{f}}} \sigma \sin ^{2} \psi-\frac{2 v_{\mathrm{f}}}{E_{\mathrm{f}}} \sigma
$$

where $E_{\mathrm{f}}$ is the Young's modulus, $v_{\mathrm{f}}$ the Poisson's ratio of the film and $\sigma=\sigma_{\mathrm{xx}}$.

Complementary stress measurements are always done using curvature measurements (Stoney formula) during the same deposition sequence but using thinner silicon wafer substrates for which buckling is not observed [13]. The stresses obtained using $\mu$ SXRD on adherent regions of $\mathrm{W}$ and $\mathrm{Au}$ films are comparable to those deduced from curvature measurements. Furthermore, similar results are obtained for any (hkl) diffracting planes considered for $\mathrm{W}$ and $\mathrm{Au}$ films and the linear behavior for the $\sin ^{2} \Psi$ plot is almost observed for all measurements. Finally, the relative uncertainty on stress values is estimated to be about $10 \%$. 

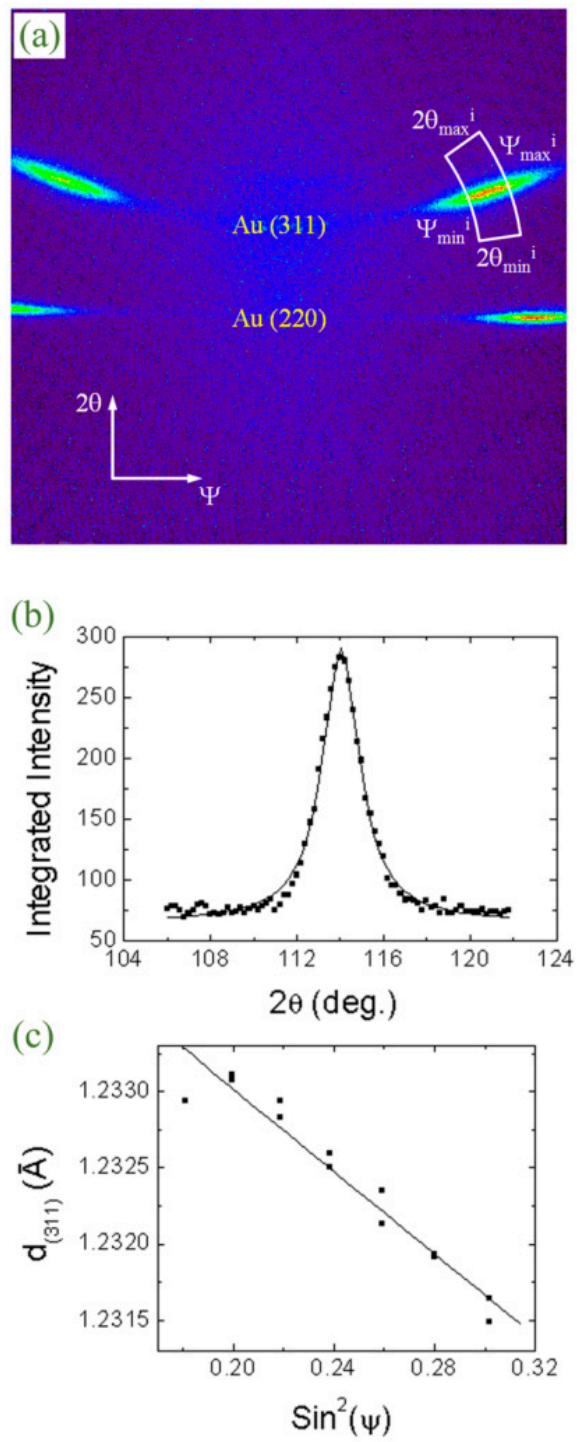

Figure 2. Principle of the $\sin ^{2} \Psi$ technique applied to a $2 \mathrm{D}$ diffraction pattern. (a) Diffraction pattern obtained from the Au film. Intensity is integrated in a $\left[\psi_{\min }^{\mathrm{i}}, \psi_{\max }^{\mathrm{i}}\right]$ delimited interval over $\mathrm{a}\left[2 \theta_{\min }, 2 \theta_{\max }\right]$ range. (b) Plot of the diffraction peak given by the previous intensity integration. The Lorentzian fit is shown (c) " $d$ vs. $\sin ^{2} \Psi$ " plot obtained after integration over 13 intervals.

\section{Finite Element Modeling of Thin Film Buckling}

The actual buckling area spans tens to hundreds of microns and has the thickness of 150-630 nm, so it would be considered as a thin shell in FEM, where transverse shear flexibility is not considered as an important part of the deformation. An initial domain of shell is modeled according to the buckling edges in the experimental image with the pixel calibration. This is the initiation zone where the wrinkles can be generated (Figure 3). In this analysis, the plane geometries of the debonded films are given, which can be picked out from the optical image of the buckling patterns, supposed to be plane before the buckling of the wrinkle.

The FEM calculations are carried out using the software ABAQUS 6.12, ABAQUS Inc (Dassault Systèmes, France). An eight-node doubly curved thin shell with five degrees of freedom per node is used to model the films. Thin shell elements may provide enhanced performance by reducing the number of degrees of freedom to just five. The Kirchhoff hypothesis, which assumes that lines initially normal to the shell's reference surface remain normal to that surface during the deformation, is imposed numerically in the element. 
The surface of the shell is defined as the $(O, x, y)$ plane and the out-of-plane displacement is $(w(x)$ $y)$ ), see Figure 3. In order to take into account the presence of the substrate, the unilateral displacement condition, $w(x, y) \geq 0$, is introduced into the model.

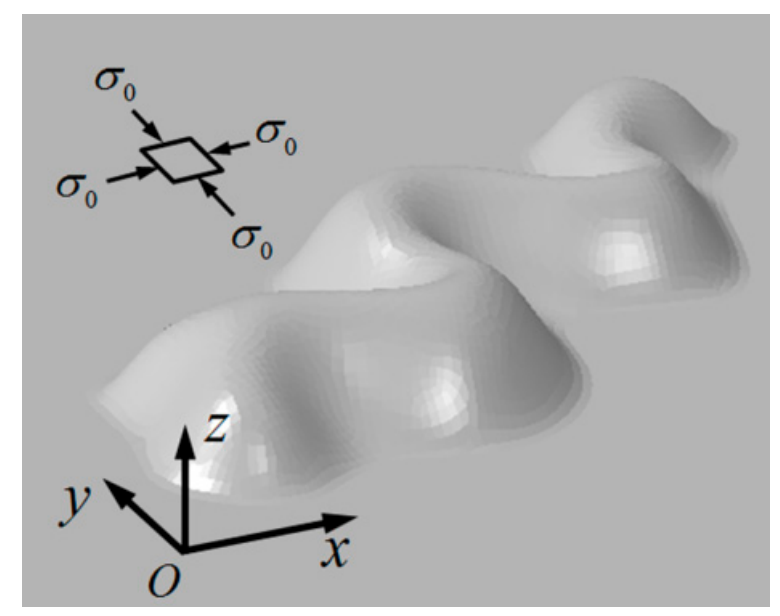

Figure 3. Model of thin film buckling after delamination: a nonlinear shell on a stiff substrate with both bonded and debonded region.

\subsection{Imperfections}

Thin film buckling studies are generally started with eigenvalue buckling estimates. In our work, imperfections based on the random combination of buckling eigenmodes are introduced in the FEM analyses to take into account the film buckling [31]. The next step of a typical buckling analysis is to perform a nonlinear calculation of large deformation analysis, and finally to investigate the patterns of buckled films which are caused by initial geometric imperfections. In this way, unstable post buckling response can be addressed.

For the buckling analysis of thin films, an imperfection related, for instance, to substrate roughness must be introduced at the flat film/substrate interface to cause it to undulate. Indeed, a flat film may never buckle numerically over critical load levels because the model has absolutely no pre- buckled displacement in the post-buckled mode and, thus, no ability to switch to the buckling patterns of thin film. Presumably, an imperfection even very small would be the most critical parameter to get buckling. In this work, the imperfections are always small enough to ensure that the solution is accurate. The imperfection magnitude is taken as $1 \%$ of the shell thickness. Once damage has formed, its shape is virtually independent of details of imperfection since the imperfection amplitude is so small.

\subsection{Loads}

For the wrinkles, the loading consists of an initial strain $\varepsilon_{0}<0$ applied uniformly to the shell $\left(\Sigma_{\mathrm{xx}}=\Sigma_{\mathrm{yy}}=\Sigma_{0}, \Sigma_{\mathrm{xy}}=0\right)$, which is caused by the equi-biaxial residual stresses, $\sigma_{0}$, generated during thin film deposition [5]. The strain loads will generate equi-biaxial residual stresses in the well bonded film part and released stresses in the buckled film parts in FEM simulations. The $630-\mu \mathrm{m}$-thick silicon substrate is assumed to be rigid and plane. As a result, the films in the vicinity of the wrinkles can be considered as clamped $(w=0, \partial w / \partial x=\partial w / \partial y=0)$ on the substrate. In fact, the substrate controls the in-plane displacement of the adhesive film outside the debonded region, as depicted in Figure 3. The residual negative strains (related to compressive stresses) in the adherent part are evaluated from the $\mu \mathrm{SXRD}$ stress measurements.

\section{Results and Discussion}

It is now well known that the stresses are strongly relaxed in the buckled part of the thin films mainly thanks to theoretical studies and numerical calculations. Of course, Raman spectroscopy as 
well as, more recently, $\mu$ SXRD have also shown stress relaxation. The average membrane stresses of the film in the $x$-direction have been considered in both the adherent and buckled regions in the FEM approach. This stress component is chosen for comparison with the experimental stresses measured by HSXRD.

As expected, buckling structures appear in the numerical shell model. These are generated by the equi-biaxial compression due to residual stresses. The in- plane geometry of the wrinkles has been measured using an optical microscope. The numerical results for the buckling are shown in Figures 4-7, where the displacement maps of the debonded film are compared to the optical microscope image of the delaminated regions. A fair agreement is found between the numerical film pattern and the delamination topology observed by optical microscopy.

In a previous work, Goudeau et al. (2003) [13] performed measurements on buckling which appear in thin $\mathrm{Au}$ and $\mathrm{W}$ films deposited onto nominal flat silicon substrates and obtained the distribution of stresses associated with these buckling as shown in Figure $4 a, b$ and Figure 6. Buckles are scanned using a 10-15 $\mu \mathrm{m}$ step size. For the W film corresponding to region III in Figure 1, the comparison of the in-plane geometries between the optical image and the FEM simulation is shown in Figure 4a. The results show a good agreement between the numerical and experimental methods. In Figure $4 b$, the X-ray measured stress map shows that the stress in the adherent film outside the delaminated region is about $-4000 \mathrm{MPa}$ and reaches about $+1000 \mathrm{MPa}$ at the top of the buckling. In the simulation, we observed the same trend when choosing the value of equi-biaxial residual stress in the adhesive region to be about $-4000 \mathrm{MPa}$, which leads to a value of $+1100 \mathrm{MPa}$ at the top of the buckling. The existence of huge compressive stresses in $\mathrm{W}$ films is mainly due to the deposition process (ion beam sputtering). Indeed, the deposited atom energy is relatively high (between 100 and $1000 \mathrm{eV}$ ) which leads to the well-known "atomic peening" effect [32]. A large number of defects are produced in the crystallographic lattice (self-interstitials, for instance) leading to strong distortions which can be revealed by an increase of the stress-free lattice parameter with respect to the reference value. In addition, the grain sizes are nanometric, considerably influencing the yield stress of $\mathrm{W}$ (value increase compared to coarse grain value), and thus could explain the presence of such large residual stresses in the film. Furthermore, the geometry of the system thin film/rigid substrate confers specific mechanical properties to the film.

Figure 5 shows the stress map obtained by FEM calculation compared to the output of a $\mu$ SXRD scan performed over a circular blister with a diameter of $54 \mu \mathrm{m}$ in a 630-nm-thick Au film on Si. The stress map obtained by $\mu S X R D$ shows that the stress in the adherent film in the vicinity of the blister is about - $400 \mathrm{MPa}$ while it vanishes to around $0 \mathrm{MPa}$ in the middle of it. The FEM stresses vary from $-400 \mathrm{MPa}$ to $+21 \mathrm{MPa}$. For Au films, the stress amplitude in the adherent part is slightly less than the yield stress value (500 MPa) observed in the literature for such films, i.e., same order of grain sizes [33]. Plasticity certainly occurs at the edge of the blister [34].

Figure $6 \mathrm{~b}$ shows the stress map over an isolated telephone-cord wrinkle in the $\mathrm{W}$ film. The biaxial stress in the adherent region is about $-6000 \mathrm{MPa}$ while it reaches a value of about $+1000 \mathrm{MPa}$ at the top of the wrinkles in $\mu$ SXRD experiment; the FEM stresses vary from $-6000 \mathrm{MPa}$ to $+949 \mathrm{MPa}$ in Figure $6 b$.

The output of a $\mu$ SXRD scan performed over a circular blister (diameter $=40 \mu \mathrm{m}$ ) of a 630-nm-thick $\mathrm{Au}$ film on $\mathrm{Si}$ is shown in Figure 7a. The scan was performed with a $2-\mu \mathrm{m}$ step size using 300 s exposure time at each step for diffraction pattern recording. The stress map shows that the stress in the adherent film in the vicinity of the blister is about $-400 \mathrm{MPa}$ while it vanishes to around $0 \mathrm{MPa}$ in the middle of it. The stress profiles across the blister in the experimental and FEM results are in overall good agreement (Figure $7 \mathrm{~b}$ ). The transition is sharp for finite element modeling (see the explanation below) while it is smoothed for X-rays. The effect in this last case is explained by the beam size, which is almost twice the step size. 

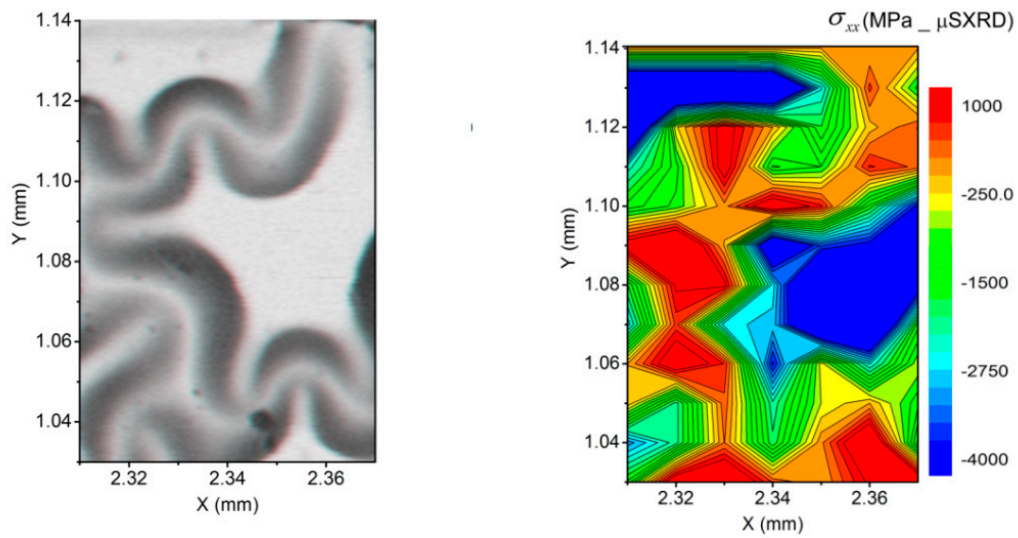

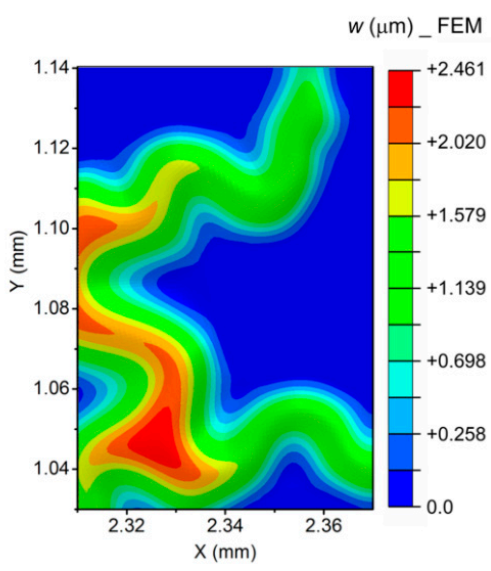

(a)

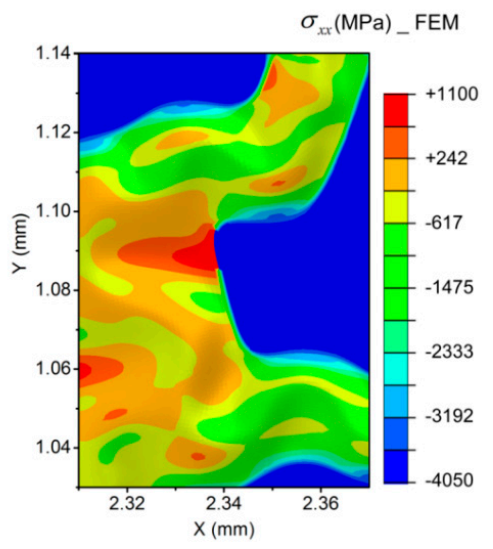

(b)

Figure 4. (a) Comparison (vertical) of the deformation of the delaminated film between the finite element method (FEM) result and optical measurement. The deformation intensity scale $\mathrm{w}$ in the $\mathrm{z}$ direction is expressed in $\mu \mathrm{m}$ units. (b) Comparison (vertical) of the stress maps between the numerical and the micro-scanning X-ray diffraction ( $\mu \mathrm{SXRD}$ ) results. The stress intensity scale $\sigma_{\mathrm{xx}}$ is expressed in MPa units for both maps.
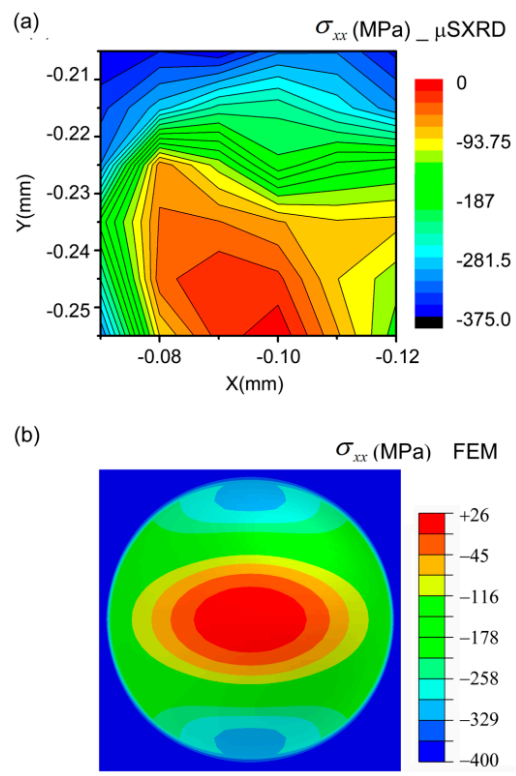

Figure 5. (a) $\mu$ SXRD results of an approximately 54- $\mu$ m-diameter blister in a 630-nm-thick Au film deposited on Si. (b) Numerical average membrane stress in $x$-direction. 
In these four buckling examples, a very good agreement is found between FEM and $\mu$ SXRD stress maps since the minimum and maximum of stresses appear almost at the same locations with the same amplitude for both methods. The main difference between $\mathrm{W}$ and Au materials is that plastic damage occurs in the latter at the edges, i.e., the circumference of the buckle. Another difference is related to stress release since the stress is almost 0 at the top for Au blisters while it is in tension (positive stress) for W. Let us remember that there exists an in-depth stress gradient through the film thickness in the buckling region. This is not taken into account in our comparison since $\mu$ SXRD only provides an average value through the film thickness.
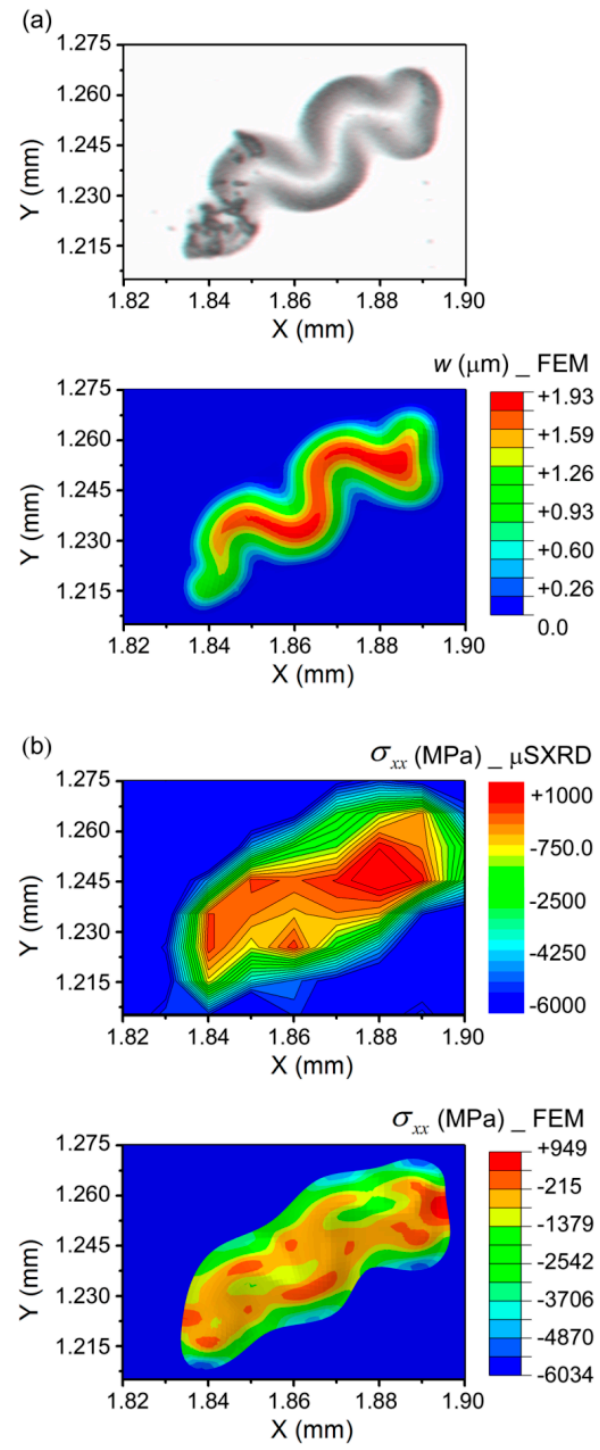

Figure 6. (a) Optical microscope image of an isolated wrinkle in a 300-nm-thick W film and the buckling deformation obtained by FEM. (b) Corresponding stress maps obtained by $\mu$ SXRD and FEM.

In the FEM calculation, the bonded films outside the buckling regions are considered as constrained by the stiff substrates. As a result, the stresses are just released in the buckling region while the levels of the initial residual stresses remain constant in the bonded region. Therefore, a break of the stress distribution is presented at the buckling edges. This indicates that the stresses are released suddenly from the bonded film to the wrinkles and blisters in our FEM results. This may be improved by introducing the adhesion model at the interface between the film and the substrate $[5,35]$. 
The precision for $\mu \mathrm{SXRD}$ stress mapping could be improved by taking into account the variation of the normal to the sample surface adding a correction to the " $d$ vs. $\sin ^{2} \Psi$ " plot during the buckling scan [36]. For instance, a maximum deviation of $12^{\circ}$ may be expected for an Au blister with a width of $40 \mu \mathrm{m}$, see Figure 7. This effect could be corrected if the coordinates of the normal to the blister are known. This could be done by applying atomic force microscopy in tapping mode [37]. Otherwise, the value of the angular position of the maximum intensity in the diffraction ring is well known and does not change during the buckling scan. An extension of the $\Psi$-angular domain of measurement would also greatly increase the precision of stress determination. On the other hand, the surface curvature does not affect the precision of stress measurement; for instance, the radius of surface curvature in Au film blisters (135 microns) is much larger than the X-ray spot size $\left(\mu \mathrm{m}^{2}\right)$ [38]. Moreover, $\mu$ SXRD is not suitable for the dynamic measurement of the delaminating process, such as the propagation of telephone-cord and straight-sided buckling [5,39].
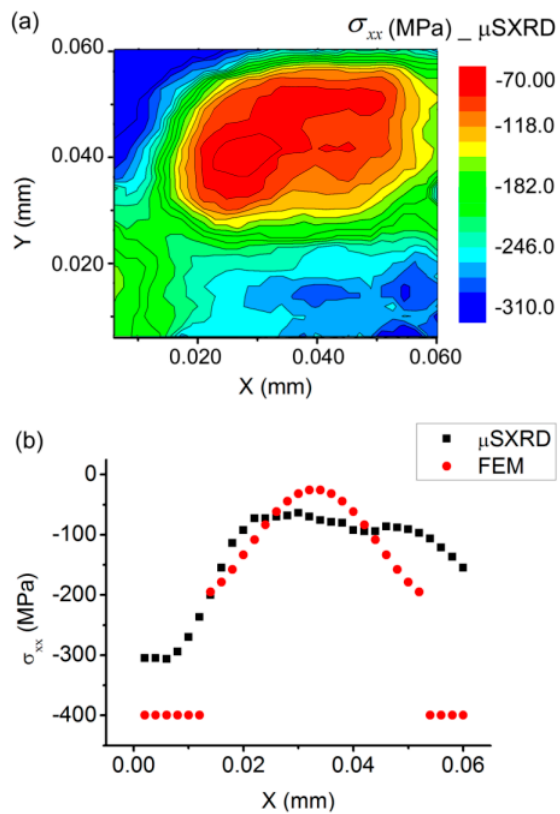

Figure 7. (a) Stress map by $\mu$ SXRD of the Au blister with a width of $40 \mu \mathrm{m}$. (b) Comparison of the stress profiles along the cross section of the Au blister obtained by $\mu$ SXRD and FEM.

\section{Conclusions}

Studies on thin film buckling on stiff substrates by micro-scanning X-ray diffraction ( $\mu \mathrm{SXRD})$ and finite element method have shown that the stresses are released when the film buckled away from the substrate. $\mu \mathrm{SXRD}$ experimental results on $\mathrm{Au}$ and $\mathrm{W}$ films after deposition have been presented. It is confirmed that $\mu \mathrm{SXRD}$ is able to investigate the stress distribution of film buckling at the micron scale. This leads directly to accurate stress maps of the investigated wrinkles and blisters.

Buckling geometry can be extracted from optical measurements and then introduced into the finite element model to simulate the buckling behavior. Very accurate values at the edges of the delamination geometry are directly measured from optical images and especially for complex wrinkles such as those obtained for $\mathrm{W}$ films. This information is of great interest since the nonlinear calculation of instability of the thin film model in FEM has been performed taking into account the measured residual stress and the geometric parameters extracted from optical measurements. With such an approach, we can easily model complex wrinkles since the propagation of the crack occurring at film/substrate interface is ignored. However, sharp variations of stresses at edges are not realistic. This problem could be improved by taking into account film adhesion to the substrate and interface sliding.

Microdiffraction measurements can be improved further for quantitative comparison with FEM stress maps. First, the spatial resolution used in this study is too large with respect to the buckling 
dimensions. X-ray beam size of less than one micron for such polycrystalline films with nanometric grain sizes would be adequate. Second, the total stress tensor is needed since FEM allows the calculation of all components.

Author Contributions: Conceptualization, P.G.; software, N.T.; validation, S.B.W..; formal analysis, H.J.; writing — original draft preparation, P.G. writing — review and editing, N.T.

Funding: The Advanced Light Source is supported by the Director, Office of Science, Office of Basic Energy Sciences, Materials Sciences Division, of the U.S. Department of Energy under Contract No. DE-AC02-05CH11231 at Lawrence Berkeley National Laboratory. The authors are grateful to the financial supported by the National Key Basic Research Program (973 Program) of China (No. 2012CB937500) and NSFC (No. 11072174).

Acknowledgments: The authors would like to thank Philippe Guerin for thin film deposition at Pprime institute.

Conflicts of Interest: The authors declare no conflict of interest.

\section{References}

1. Thornton, J.A.; Hoffman, D.W. Stress-related effects in thin films. Thin Solid Films 1989, 171, 5-31. [CrossRef]

2. Wang, S.B.; Jia, H.K.; Li, L.A.; Sun, H.; Cui, D.Q.; Guo, Z.S.; Xue, X.L. Experimental investigation on cumulative propagation of thin film buckling under cyclic load. Sci. China Technol. Sci. 2011, 54, 1371-1375. [CrossRef]

3. Cordill, M.J.; Bahr, D.F.; Moody, N.R.; Gerberich, W.W. Adhesion measurements using telephone cord buckles. Mater. Sci. Eng. A 2007, 443, 150-155. [CrossRef]

4. Yu, S.J.; Zhang, Y.J.; Chen, M.G. Telephone cord buckles in wedge-shaped Fe films sputtering deposited on glass substrates. Thin Solid Films 2009, 518, 222-226. [CrossRef]

5. Faou, J.Y.; Parry, G.; Grachev, S.; Barthel, E. How Does Adhesion Induce the Formation of Telephone Cord Buckles? Phys. Rev. Lett. 2012, 108, 116102. [CrossRef] [PubMed]

6. Hutchinson, J.W.; Suo, Z. Mixed mode cracking in layered materials. Adv. Appl. Mech. 1992, 29, 63-191.

7. Wang, Q.; Yin, Y.; Xie, H.; Liu, J.; Yang, W.; Chen, P.; Zhang, Q. Buckling modes of polymer membranes restricted by metal wires. Soft Matter 2011, 7, 2888-2894. [CrossRef]

8. Cleymand, F.; Colin, J.; Coupeau, C.; Grilhé, J. Stability of wrinkling patterns: From straight-sided to worm-like structures. Eur. Phys. J. Appl. Phys. 2002, 17, 173-178. [CrossRef]

9. Audoly, B. Stability of Straight Delamination Blisters. Phys. Rev. Lett. 1999, 83, 4124-4127. [CrossRef]

10. Xue, X.; Wang, S.; Zeng, C.; Bai, H.; Li, L.; Wang, Z. Buckling-delamination and cracking of thin titanium films under compression: Experimental and numerical studies. Surf. Coat. Technol. 2014, 244, 151-157. [CrossRef]

11. Panicaud, B.; Grosseau-Poussard, J.L. Stress analysis of local blisters coupling Raman spectroscopy and X-ray diffraction. Correlation between experimental results and continuous damage modelling for buckling in an iron oxide/phosphated iron system. Appl. Surf. Sci. 2010, 257, 1282-1288. [CrossRef]

12. Guerain, M.; Grosseau-Poussard, J.-L.; Goudeau, P. Local stress determination in chromia-former thanks to Micro-Raman Spectroscopy: A way to investigate spontaneous delamination processes. J. Appl. Phys. 2013, 113, 063502. [CrossRef]

13. Goudeau, P.; Villain, P.; Tamura, N.; Padmore, H.A. Mesoscale X-ray diffraction measurement of stress relaxation associated with buckling in compressed thin films. Appl. Phys. Lett. 2003, 83, 51-53. [CrossRef]

14. Martins, J.A.; Cardoso, L.P.; Fraymann, J.A.; Button, S.T. Analyses of residual stresses on stamped valves by X-ray diffraction and finite elements method. J. Mater. Process. Technol. 2006, 179, 30-35. [CrossRef]

15. Mezin, A. Coating internal stress measurement through the curvature method: A geometry-based criterion delimiting the relevance of Stoney's formula. Surf. Coat. Technol. 2006, 200, 5259-5267. [CrossRef]

16. Abadias, G.; Chason, E.; Keckes, J.; Sebastiani, M.; Thompson, G.B.; Barthel, E.; Doll, G.L.; Murray, C.E.; Stoessel, C.H.; Martinu, L. Review Article: Stress in thin films and coatings: Current status, challenges, and prospects. J. Vac. Sci. Technol. A 2018, 36, 020801. [CrossRef]

17. Korsunsky, A.M.; Salvati, E.; Lunt, A.G.J.; Sui, T.; Mughal, M.Z.; Daniel, R.; Keckes, J.; Bemporad, E.; Sebastiani, M. Nanoscale residual stress depth profiling by Focused Ion Beam milling and eigenstrain analysis. Mater. Des. 2018, 145, 55-64. [CrossRef] 
18. Salvati, E.; Korsunsky, A.M. An analysis of macro- and micro-scale residual stresses of Type I, II and III using FIB-DIC micro-ring-core milling and crystal plasticity FE modelling. Int. J. Plast. 2017, 98, 123-138. [CrossRef]

19. Guerain, M.; Goudeau, P.; Grosseau-Poussard, J.-L.; Geandier, G.; Panicaud, B.; Tamura, N.; Kunz, M.; Dejoie, C.; Micha, J.-S.; Thiaudiere, D. Residual stress analysis at different length scales in thermally grown oxide films on metals combining Raman spectroscopy and X-ray diffraction. J. Appl. Phys. 2017, 122, 195105. [CrossRef]

20. De Wolf, I.; Senez, V.; Balboni, R.; Armigliato, A.; Frabboni, S.; Cedola, A.; Lagomarsino, S. Techniques for mechanical strain analysis in sub-micrometer structures: TEM/CBED, micro-Raman spectroscopy, X-ray micro-diffraction and modeling. Microelectron. Eng. 2003, 70, 425-435. [CrossRef]

21. Lai, B.; Maser, J.; Paunesku, T.; Woloschak, G.E. Report on the Workshop of Biological Applications of X-ray Microbeams. Int. J. Radiat. Biol. 2002, 78, 749-752. [CrossRef] [PubMed]

22. Larson, B.C.; Yang, W.; Ice, G.E.; Budal, J.D.; Tischler, J.Z. Three-dimensional X-ray structural microscopy with submicrometre resolution. Nature 2002, 415, 887-890. [CrossRef] [PubMed]

23. Miao, J.; Ishikawa, T.; Johnson, B.; Anderson, E.; Lai, B.; Hodgson, K. High Resolution 3D X-ray Diffraction Microscopy. Phys. Rev. Lett. 2002, 89, 088303. [CrossRef] [PubMed]

24. Audoly, B. Mode-dependent toughness and the delamination of compressed thin films. J. Mech. Phys. Solids 2000, 48, 2315-2332. [CrossRef]

25. Djaziri, S.; Renault, P.-O.; Le Bourhis, E.; Goudeau, P.; Faurie, D.; Geandier, G.; Mocuta, C.; Thiaudière, D. Comparative study of the mechanical properties of nanostructured thin films on stretchable substrates. J. Appl. Phys. 2014, 16, 093504. [CrossRef]

26. Faurie, D.; Castelnau, O.; Renault, P.-O.; Patriarche, G.; Brenner, R.; Le Bourhis, E.; Goudeau, P. Elastic properties of polycrystalline gold thin films: Simulation and X-ray diffraction experiments. Surface $\mathcal{E}$ Coatings Technology 2006, 201, 4300-4304. [CrossRef]

27. Tamura, N.; Celestre, R.S.; MacDowell, A.A.; Padmore, H.A.; Spolenak, R.; Valek, B.C.; Meier Chang, N.; Manceau, A.; Patel, J.R. Submicron X-ray diffraction and its applications to problems in materials and environmental science. Rev. Sci. Instrum. 2002, 73, 1369-1372. [CrossRef]

28. Tamura, N.; MacDowell, A.A.; Spolenak, R.; Valek, B.C.; Bravman, J.C.; Brown, W.L.; Celestre, R.S.; Padmore, H.A.; Batterman, B.W.; Patel, J.R. Scanning X-ray microdiffraction with submicrometer white beam for strain/stress and orientation mapping in thin films. J. Synchrotron Radiat. 2003, 10, 137-143. [CrossRef]

29. Noyan, I.C.; Cohen, J.B. Residual Stress-Measurement by Diffraction and Interpretation; Springer: New York, NY, USA, 1987.

30. Serruys, W.; Van Houtte, P.; Aernoudt, E.; Peters, J. Why Are X-ray Measurements of Residual Stresses Different from Mechanical Residual Stress Measurements? CIRP Ann. 1988, 37, 527-530. [CrossRef]

31. Jia, H.K.; Wang, S.B.; Goudeau, P.; Li, L.A.; Xue, X.L. Investigation of buckling transition from straight-sided to telephone-cord wrinkles in Al films. J. Micromech. Microeng. 2013, 23, 045014. [CrossRef]

32. Durand, N.; Badawi, K.F.; Goudeau, P. Residual stresses and microstructure in tungsten thin films analyzed by X-ray diffraction-evolution under ion irradiation. J. Appl. Phys. 1996, 80, 5021-5027. [CrossRef]

33. Wang, L. Investigation of the mechanical behavior of freestanding polycrystalline gold films deposited by evaporation and sputtering methods. In Materials Science; Auburn University: Auburn, AL, USA, 2007; p. 195.

34. Coupeau, C.; Goudeau, P.; Belliard, L.; George, M.; Tamura, N.; Cleymand, F.; Colin, J.; Perrin, B.; Grilhé, J. Evidence of plastic damage in thin films around buckling structures. Thin Solid Films 2004, 469-470, 221-226. [CrossRef]

35. Faou, J.Y.; Parry, G.; Grachev, S.; Barthel, E. Telephone cord buckles-A relation between wavelength and adhesion. J. Mech. Phys. Solids 2014, 75, 93-103. [CrossRef]

36. Matejicek, J.; Sampath, S. Intrinsic residual stresses in single splats produced by thermal spray processes. Acta Mater. 2001, 49, 1993-1999. [CrossRef]

37. Goudeau, P.; Renault, P.O.; Villain, P.; Coupeau, C.; Pelosin, V.; Boubeker, B.; Badawi, K.F.; Thiaudiere, D.; Gailhanou, M. Characterization of thin film elastic properties using X-ray diffraction and mechanical methods: Application to polycrystalline stainless steel. Thin Solid Films 2001, 398-399, 496-500. [CrossRef]

38. Dionnet, B.; François, M.; Sprauel, J.M.; Nardou, F. The influence of cylindrical geometry on X-ray stress tensor analysis. II. Applications. J. Appl. Cryst. 1999, 32, 883-891. [CrossRef] 
39. Yu, S.J.; Xiao, X.F.; Chen, M.G.; Zhou, H.; Chen, J.; Si, P.Z.; Jiao, Z.W. Morphological selections and dynamical evolutions of buckling patterns in SiAlNx films: From straight-sided to telephone cord or bubble structures. Acta Mater. 2014, 64, 41-53. [CrossRef] 